But Nawaschin and Guignard have further shown that, in addition to the normal fertilisation of the egg-cell by one of these pollen-nuclei (spermatozoid), the other spermatozoid fuses with the upper polar nucleus of the embryo-sac, and thus brings about a sort of secondary fertilisation-a fertilisation of the cell which, by further division, produces the endosperm. For it will be remembered that the secondary nucleus arises by the fusion of the two polar nuclei.

Divested of details, while one spermatozoid nucleus carries material from the pollen into the egg-cell, and so transfers the influence of the male to the egg and its resulting embryo-plant, the other spermatozoid carries a similar share of material from the pollen into the polar nucleus, and thus transfers the influence of the male to the secondary nucleus of the embryo-sac, and thus to the endosperm.

Now the endosperm is regarded as the representative of the prothallus of the higher Cryptogams, and acts as the nurse for the embryo; and the upshot of the foregoing is that not only is the embryo (and through it the future plant) affected by the male hereditary substance, which can be easily seen eventually in cross-bred plants and hybrids of all sorts, but the rudimentary prothallus generation also receives its dose of male substance, and the question arises whether the effect of this dose can be traced in any visible way.

Let us now turn to another set of events. It has been known for some time that different varieties or races of the maize or "Indian corn," although all belonging to the same species, show remarkable differences, not only in the size, shape, colour, \&c., of their well-known grains, but also in the nature of their nutritious contents-i.e. what is usually termed the "flour" or "meal." Now, this "flour" is the endosperm, and contains the nutritious substances for the growing embryo. In the typical case its cells are crammed with starch grains, well known in domestic economy as "corn-flour." But in certain races of maize there are no (or very few and small) starch grains, but a slimy substance (dextrin?), mixed with sugar, fills the cells. Again, the outermost layer of cells bounding the endosperm-the so-called aleurone layer - has, not starch grains, but nitrogenous reserve stores for its principal contents, and in some races bright purple or other colouring material as well, which shines through the skin of the grain (testa and pericarp), and so gives the hue to the fruit.

The economical importance of the maize ${ }^{1}$ has stimulated many observers to experiment in hybridising the existing races, and the principal object of this article is to show how some recently observed results in this connection have-quite unexpectedly-come to cast new lights on the phenomena above referred to, and to illustrate the potency of pollen in a way not hitherto suspected.

These researches are due to De Vries, ${ }^{2}$ and to Correns, who have found that if cross-breeding is carried on between races of maize with a starchy yellow endosperm and violet aleurone layer, and races with a sugary hyaline endosperm and colourless aleurone layer, for instance, very marked effects of the pollen can be traced in the endosperm of the directly resulting grain, quite apart from the effects eventually discernible in the resulting crossbred plant to which the embryo gives rise, and which, of course, are only visible in the succeeding crop. These visible effects of the pollen are expressed only in the colour and chemical contents of the endosperm.

1 The meal is used for Polenta, corn-flower, pop-corn, \&c., and after the manner of malt in distilling spirits. The young grains are cooked. 'The sugary sap is used for fermented drinks, Chica, Pulque de Mahiz, \&c. The straw for paper, \&c. The raw grain, young shoots, \&c., for fodder. Some races are of horticultural value, and so on. In $1893,32,000,000$ cwts. were imported into this country (see "Official Guide to the Museums of Economi Botany, Kew." No. 2, 1895, p. 64).

Comptes renatus, $4 / 12 / 99$, No. 23 , vol. cxxix. p. 973.

3 Ber. d. d. Bot. Ges. 1899, vol. xvii. p. 4 Io.

NO. I 585 , VOL. 6I]
Thus, the result of pollinating a race (A) which has a colourless aleurone layer, by a race (B) with a coloured one, may be that the ripening grain of A now obtains an endosperm with its aleurone layer the same colour as $\mathrm{B}$; or if A has a starchy endosperm and $\mathrm{B}$ a slimy and sugary one, the endosperm of A becomes sliniy and sugary, and so on.

The effect of the pollen of $\mathrm{B}$, so directly expressed in the resulting endosperm of $\mathrm{A}$, does not necessarily show itself in the converse case, however ; and if the pollen of $B$ alters the colour of the aleurone layer in the grain of $A$, the effect of the reciprocal cross may be that the pollen of $\mathrm{A}$ alters - not the colour of the aleurone, butthe contents of the endosperm of $\mathrm{B}, e . g$. from starchy to sugary, and so on.

Correns points out that no visible change in the embryo, or in the size of the endosperm, or size and shape of the grain can be thus directly producedwhatever may be the more distant effects visible in the cross-breed resulting from the sowing of the grain next year.

There seem to be two possible ways of explaining these remarkable phenomena.

First, we may suppose that the spermatozoid nucleus of the pollen tube, having fused with the egg-cell, so alters the embryo that as it grows it affects the endosperm (e.g. by secreting some enzyme) and so alters the colour of the aleurone layer on the nature of the cellcontents; this hypothesis is supported in part by the fact that while it is easy to produce sugary endosperms in grains of races which normally develop starchy ones, the converse action is not obtained.

The second hypothesis is that we have in these phenomena the direct visible effects of the fusion of the second pollen tube nucleus (spermatozoid) with the polar nuclei (from which the endosperm results). In other words, we have here a hybrid endosperm as well as a hybrid embryo.

Both De Vries and Correns regard the latter explanation as the right one, and Correns points out that similar cases have been observed by Giltay in rye.

On the other hand, no visible results in the endosperm were obtained in peas and lilies, and the deep blue colour of the yellow seeds of species of Leucojum or of Peas crossed with the pollen of deep blue seeded races of the same in each case depends on the formation of blue proteid grains in the epidermis of the cotyledons.

That these positive results will lead to renewed investigations of other cases of nuclear fusion-e.g. grafthybrids and other examples of the reactions between scion and stock-may be confidently predicted, and interesting discoveries must await us. My present object is to call attention also to this excellent example of the reciprocal advantages botanical science obtains by the cooperation of workers in two totally different fields-the results from the laboratory here throwing suggestive lights on those from the seed-bed and garden, and vice versa. (See, also, Address to Botanical Section of British Association, Toronto, I 897, p. 3.)

H. MARShali WARD.

\section{ATMOSPHERIC ELECTRICITY AND} DISEASE.

AST summer I had the honour of making the acquaintance of Dr. Schliep, of Baden-Baden. He is well known to English medical specialists. He urged me to design a recording electrometer, such as would enable medical men to study atmospheric electricity. I found that he himself had made daily observations for twenty years, using a gold-leaf electroscope, which enabled him to say whether the air had strong or weak, positive or negative, electric potential, at the end of a 
water-dropping collector. He showed me that he had made an earnest study of the connection between atmospheric electricity and diseases, and I am convinced that his conclusions are of great importance. I feel, therefore, that I am doing a service in bringing before the notice of readers of NATURE the following account of a paper, by Dr. Schliep, in Sonderabdruck aus Deutsche Medizinal-Zeitung.

He first refers to the meteorological observations usually made, and goes on to say that our knowledge of atmospheric electricity is now as vague as was the knowledge of warmth before thermometric observation became systematic. Dove, in 1837 , and Humboldt, in his Cosmos, mention the importance of the study of atmospheric electricity. Dr. Graves, of Dublin, made observations and said: "Practically these experiments are of importance, because some causes of the periodicity of certain acute diseases, their decrease and increase at certain hours of the day, may be deduced from them." Hufeland also refers to this matter. Dr. Buzorine, of Würtemburg, in I 841 , drew attention to the fact that during the cholera epidemics of the third decade of this century, there was a prevalence of negative electrification of the atmosphere. Dr. Pallas, a French physician, wrote on this subject in 1847 , and Dr. Craigr, an Englishman, wrote about it in 1859 .

Dr. Schliep now describes his method of observation with the gold-leaf electroscope, and gives the following results. The first part of these may be said to be well known to us. What seems to me of most importance is the effect on organisms.

Atmospheric electricity is generally positive. If the sky is covered, the potential decreases or shows variations, and is from time to time negative. During rain, negative potential is often observed. 'The approach of a thunderstorm is generally marked by great alteration towards the negative, followed by considerable oscillations in both directions, with a predominance of negative. Usually the positive potential is higher and more regular during the night than during the daytime. From 9 p.m. to 3 a.m. the potential changes little. It diminishes by daybreak, reaches its lowest value at 3 p.m., then increases and reaches the maximum at 9 p.m. There is, therefore, a minimum during the day, and an almost constant maximum during the greater part of the night; that is to say, there is only one daily period. These facts are decluced from the use of the registering apparatus of Mascart. Other observers have found two maxima and two minima, but they are probably only accidental variations. In every month there are a number of days on which negative electrification can be observed, others, and they are rare, when there is scarcely any electrification noticeable. On most days there is positive potential.

According to Marié Davy's observations in Paris, and Dr. Schliep's at Baden, there are two days of positive electrification for 28 negative. The winter shows higher potential than the summer.

Many terrestrial phenomena, such as earthquakes, are said by trustworthy observers (Schubler, Humboldt) to greatly influence atmospheric electricity. After an auroral display there is strong positive electrification. At greater elevations, especially on steep and high mountains, the electrification is greater.

Dr. Schliep makes the following statements about the influence of atmospheric electricity on human beings:--Negative electrification is tiring, positive is exciting. Positive is favourable to the process of oxidation, increases metabolism, circulation and secretion. It may be that the increased formation of ozone has an influence in this way also, but we can imagine a direct stimulating influence of positive electricity on the nervous system. We may affirm the existence of this influence as, during strong electrification, disturbances of the normal condition are noticeable, as in sleeplessness, the existence of states of anxiety, hysteria, neuralgia, and even sometimes inflammation of the respiratory organs. One interesting confirmation of this opinion is found in the observations which Eyselein has made regarding the behaviour of nervous people, as influenced by the amount of ozone in the air. It seems that if there is too little ozone, and especially if it completely and suddenly disappears, there is considerable bodily disturbance; whilst its sudden reappearance causes a quick return of healthy feeling. It has also been proved that a continuance of much ozone is not unfavourable to health. Ozone intensity less than No. Io of Zender's scale, but not mush less, has a tonic effect on nervous people, but intensities from 9 to 4 cause disturbances. These facts agree with the observations I have made in regard to the health of my patients, as affected by atmospheric electricity. From these observations I conclude that a certain amount of nervous disorder, as well as a power of resistance, are associated with positive electrification. As in many other cases, there is therefore in this instance the possibility of having too much of a good thing.

Unhealthy symptoms, unfavourable to tissue-change, accompany negative electrification. Feelings of fatigue and lassitude, exhaustion of the nervous system, arrest of perspiration, loss of tone in the blond-vessels, accompany negative electrification. Congestion, bilious and apoplectic attacks and hæmorrhages are the results The development of bad gas, processes of decomposition, and increase of bacilli are the accompanying phenomena. Certain forms of disease, as angina, pneumonia, herpes, may, to extents depending upon local conditions, increase with negative electricity, and seem to be related to the souring of milk, the decomposition of meat, and the development of bad smells in the street gutters and drains. If we say that the bacilli are the cause of these things, it may be true ; but it does not explain why bacilli find more favourable conditions for their existence on some days than on others with equal warmth, moisture, air-pressure, \&c. Dr. Schliep goes on to say that we get clearer notions if we consider the difference between animal and plant metabolism.

We know the astonishing effect of a close thunderstorm-day on vegetation, the sudden breaking forth of buds, leaves and flowers, the quick development of the young seed, and the sometimes rapid growth of such plants as asparagus. Light, warmth and moisture are of course the first conditions. The observation of this remarkable phenomenon gave rise to an interesting experiment of Becquerel. He selected four hyacinth roots of equal size and sort, which he put in a weak salt solution, two in a frame of glass, the third in a frame of zinc, and the fourth in a frame of copper. The copper and zinc were attached to each other by a wire. The vegetation developed most at the negative pole, less in the neutral frame, and was least at the positive pole. It seems that the roots of plants need a negative electric medium, and the crust of the earth is constantly negative. What increases the tissue-change in plants, decreases that of the animal organism. Thus, very often, aays good for vegetation become tiresome for us. Walking in the streets causes great fatigue. All animals are tired on these days. They are the days of negative atmospheric electricity, days on which the bacilli are triumphant; wounds become septic, and germs of epidemic diseases find favourable conditions for development. It will concern bacteriology to pay attention to the facts. In balneometeorolngy, the most important object is the influence of atmospheric electricity on the anomalies of the constitution. From its better study we shall be able to derive hypotheses for our hygienic and therapeutic study, and besides the importance of geographical position, warmth, moisture, \&c., atmospheric electricity will also play an important part in the classification of climates. We shall not only have to distinguish between land and sea- 
climates, wet and dry climates, cold and warm climates, but we shall also have to characterise a climate by its electrification and define with greater exactness the terms "relaxing" and "bracing."

Perhaps we shall also be able to speak of a "spending "and a "saving" climate. We must not separate one characteristic of the climate from another and prefer it ; in nature all phenomena work more or less together, they depend on one another and exercise mutual influences on one another. The electric conditions of the air are indicated by other meteorologic records, and hence we have important sources of information which ought not to be neglected, as our methods of making direct electric observations are not yet satisfactory. One can, from the daily increase or diminution of pressure, warmth and moisture of the air, say something of its electrification.

In this connection it is of no importance whether the barometer is high or low, but whether it rises or falls. It is not important to know whether the moisture of the air is great or not; it is important to know whether the moisture decreases or increases, whether the process of condensation or of evaporation prevails.

Dr. Schliep here described at length the meaning of dew-point in hygrometric observations. He exhibited also a reduction disc made by Lambrecht, of Göttingen, a sort of circular slide rule, to facilitate the reduction of observations. He showed that the atmospheric electrification becomes negative if the average temperature and dew-point rise and if the barometer falls at the same time. If, however, the temperature and dew-point fall whilst the barometer rises, one may assume a positive electrification. He pointed out on the curves which represent his registrations at Baden during the previous ten years, that the air-pressure on one hand, and the temperature and moisture on the other, altered mostly in opposite directions. It was noticeable also that an exceptional steadiness for a few days was accompanied by the reverse of these movements as soon as the lines went far asunder. The graphic representations of meteorological phenomena show more than one would think at first sight. More plainly than lists of numbers, they allow a comparison of climatic conditions of different years or of certain periods with the statistics of the prevalent diseases during those periods.

Without a good graphic representation such statistics are never complete, however valuable the material which has been collected may be. Thus, for example, consider the work of Hippius, published in the Archives for Clin. Medic. vol. xl., about dysentery and meteorological influences upon it, in which there was an inquiry about the relation between meteorological changes and bleed. ings of the lungs with no apparent result. May not the failure of this inquiry be due to the fact that the meteorologic information was incomplete?

Dr. Schliep finishes his paper by pointing out the importance of the general meteorological observations at watering-places being under a central governmental control. The health resorts ought not to rest until they have obtained this aid from Goyernment. But he distinguishes general meteorology from the simple kind of observation which it is in the power, and ought to be the duty, of every medical man to make for himself.

JOHN PERRY.

\section{PROFESSOR EMILE BLANCHARD.}

B the death on February II, at the ripe age of 84 years, of Prof. Émile Blanchard, France has lost the doyen of its zoologists, the French Academy one of its oldest and most esteemed members, and the Paris Museum a famous entomologist. Blanchard's career was a somewhat remarkable one, and at the same time a noble example to others; for he rose to distinction from the ranks, and, when stricken by one of the most terrible of all afflictions, never swerved for an instant from the course he had to run.

Entering, at the age of fourteen, the department of entomology of the Paris Museum, in the humble capacity of what would be termed an "attendant" in our own Museum, Blanchard soon developed such a capacity for zoological work that he was transferred to the scientific staff. His first great chance of distinguishing himself occurred when he accompanied, in 1844, Prof. H. MilneEdwards on his celebrated expedition in the Santa Rosalia to Sicily, for the purpose of studying the marine fauna of the coasts. Shortly after this he was appointed Professor of Entomology to the Museum; and in 1862 received the honour of election to the French Academy of Sciences. Throughout life his chief study was entomology, the Coleoptera being his especial favourites; but he also devoted a considerable amount of attention to other branches of zoology, as well as to comparative anatomy, and in his latter years entered on the study of the geographical distribution of animals, both in past and present times. His works on Madagascar and New Zealand are well-known examples of his devotion to the latter branch of science. As a token of the esteem in which his labours were held by his fellow-workers, it may be mentioned that a genus of Carboniferous Neuroptera was named Blanchardia in his honour; while several of the fossil birds from the Miocene of France described by Milne-Edwards, such as Anas blanchardi and Palaeortyx blanchardi, received their specific titles after the subject of this notice. In addition to purely scientific memoirs (of which a long roll stands against his name) Prof. Blanchard was a frequent and admired contributor to the Revue des Deux Mondes on general subjects.

But the most remarkable circumstance connected with a large portion of his work yet remains to be told. In early life Blanchard was gifted with extraordinary acuteness of vision, and was thus enabled to make dissections of extreme delicacy (of which he has left numerous drawings and sketches) without the aid of lenses. In fact, his eyes were described by one of his early contemporaries as veritable microscopes. At the age of forty his visual powers showed serious signs of weakening. Year by year the failure of power increased, with the result that at 45 he became nearly, and at 50 totally blind. In the words of Professor Gaudry, "What more frightful affliction could have befallen a man whose life was passed in the investigation of Nature's secrets? The existence of a naturalist, who seemed specially favoured by his natural gifts and by the honours received at an age when they are obtained by few, was delivered over to the misery of darkness. If only Blanchard could have still enjoyed the delights of family life, if, while unable to see them, he could have listened to the voices of a devoted wife and beloved children! But all was gone ; he no longer saw, no longer heard anything! The visits of a few friends could alone, from time to time, afford solace to his lonely existence."

Amid the unfeigned sorrow of his confrères, his remains, on February I4, were consigned to their last resting place.

Perhaps his best-known works are "Histoire des Insectes," I 845; " Catalogue des Coléoptères du Museum d'Histoire Naturelle de Paris," I850; and "Metamor. phoses des Insectes," I868.

$$
\text { R. L. }
$$

\section{DRS. C. T. R. LUTHER AND G. RUMKER.}

WITHIN a few weeks, two observatories which have played a worthy part in the past history of astronomy have, by the death of their respective directors, suffered a notable loss, and science will deplore the removal of two well-known names from the roll of worthies, who are remembered with gratitude for much indefatigable, if not brilliant, work.

No. I 585 , voJ. 6 I] 